\title{
ACMG Recommendations for Reporting of Incidental Findings in Clinical Exome and Genome Sequencing
}

Robert C. Green, MD, MPH ${ }^{1,2}$, Jonathan S. Berg, MD, PhD³, Wayne W. Grody, MD, PhD ${ }^{4-6}$, Sarah S. Kalia, ScM, CGC ${ }^{1}$, Bruce R. Korf, MD, $\mathrm{PhD}^{7}$, Christa L. Martin, PhD, FACMG ${ }^{8}$, Amy McGuire, JD, $\mathrm{PhD}^{9}$, Robert L. Nussbaum, MD ${ }^{10}$, Julianne M. Oळaniel, MS, CGC ${ }^{11}$, Kelly E. Ormond, MS, $\mathrm{CGC}^{12}$, Heidi L. Rehm, PhD, FACMG ${ }^{2,13}$, Michael S. Watson, MS, PhD, FACMG ${ }^{14}$, Marc S. Williams, MD, FACMG ${ }^{15}$, Leslie G. Biesecker, MD $^{16}$

${ }^{1}$ Division of Genetics, Department of Medicine, Brigham and Women⿳⺈ Hospital and Harvard Medical School, Boston, Massachusetts, USA; '2Partners Healthcare Center for Personalized Genetic Medicine, Boston, Massachusetts, USA; ${ }^{3}$ Department of Genetics, University of North Carolina at Chapel Hill School of Medicine, Chapel Hill, North Carolina, USA; ${ }^{4}$ Division of Medical Genetics, Department of Human Genetics, UCLA School of Medicine, Los Angeles, California, USA; ${ }^{5}$ Division of Molecular Pathology, Department of Pathology \& Laboratory Medicine, UCLA School of Medicine, Los Angeles, California, USA; ${ }^{6}$ Division of Pediatric Genetics, Department of Pediatrics, UCLA School of Medicine, Los Angeles, California, USA; ${ }^{7}$ Department of Genetics, University of Alabama, Birmingham, Alabama, USA; ${ }^{8}$ Department of Human Genetics, Emory University School of Medicine, Atlanta, Georgia, USA; ${ }^{9}$ Center for Medical Ethics and Health Policy, Baylor College of Medicine, Houston, Texas, USA; ${ }^{10}$ Division of Genomic Medicine, Department of Medicine, and Institute for Human Genetics, University of California, San Francisco, San Francisco, California, USA; ${ }^{11}$ Illumina, Inc., San Diego, California, USA; ${ }^{2}$ Department of Genetics, Stanford University, Stanford, California, USA; ${ }^{13}$ Department of Pathology, Brigham and Women⿳⺈ Hospital and Harvard Medical School, Boston, Massachusetts, USA; ${ }^{14}$ American College of Medical Genetics and Genomics, Bethesda, Maryland, USA; ${ }^{15}$ Genomic Medicine Institute, Geisinger Health System, Danville, Pennsylvania, USA; ${ }^{16}$ National Human Genome Research Institute, National Institutes of Health, Bethesda, Maryland, USA

\section{Corresponding authors:}

Robert C. Green, MD, MPH

Division of Genetics, Department of Medicine

Partners Center for Personalized Genetic Medicine

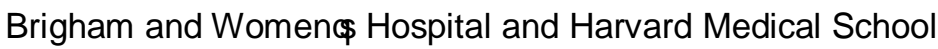

EC Alumnae Building, Suite 301

41 Avenue Louis Pasteur, Boston, MA 02115

(tel) 617-264-5834, (fax) 617-264-3018, (cell) 617-966-3216

(email) rcgreen@genetics.med.harvard.edu

Leslie G. Biesecker, MD

Chief, Genetic Disease Research Branch

National Human Genome Research Institute

49 Convent Drive room 4A56

Bethesda, MD 20892-4472

(tel) 301-402-2041, (fax) 301-402-2170, (cell) 240-400-0525

(email) leslieb@helix.nih.gov

Keywords: secondary findings, incidental findings, genome, genomic medicine, personalized medicine, whole-exome, whole-genome, sequencing 
Disclaimer: This guideline is designed primarily as an educational resource for medical geneticists and other health care providers to help them provide quality medical genetic services. Adherence to this guideline does not necessarily assure a successful medical outcome. This guideline should not be considered inclusive of all proper procedures and tests or exclusive of other procedures and tests that are reasonably directed to obtaining the same results. In determining the propriety of any specific procedure or test, the geneticists should apply his or her own professional judgment to the specific clinical circumstances presented by the individual patient or specimen. It may be prudent, however, to document in the patient's record the rationale for any significant deviation from the recommendations set forth in this guideline. 


\section{ABSTRACT}

In clinical exome and genome sequencing, there is potential for the recognition and reporting of incidental or secondary findings unrelated to the indication for ordering the sequencing but of medical value for patient care. The American College of Medical Genetics and Genomics (ACMG) recently published a policy statement on clinical sequencing, which emphasized the importance of disclosing the possibility of such results in pretest patient discussions, clinical testing, and reporting of results. The ACMG appointed a Working Group on Incidental Findings in Clinical Exome and Genome Sequencing to make recommendations about responsible management of incidental findings when patients undergo exome or genome sequencing. This Working Group conducted a year-long consensus process, including review by outside experts, and produced recommendations that have been approved by the ACMG Board. Specific and detailed recommendations, and the background and rationale for these recommendations, are described herein. We recommend that laboratories performing clinical sequencing seek and report mutations of the specified classes or types in the genes listed here. This evaluation and reporting should be performed for all clinical germline (constitutional) exome and genome sequencing, including the óormalôof tumor-normal subtractive analyses in all subjects, irrespective of age, but excluding fetal samples. We recognize that there are insufficient data on clinical utility to fully support these recommendations and we encourage the creation of an ongoing process for updating these recommendations at least annually as further data are collected. 


\section{INTRODUCTION}

Exome and genome sequencing (collectively referred to in this paper as clinical sequencing) are rapidly being integrated into the practice of medicine, ${ }^{1,2}$ The falling price of sequencing, coupled with advanced bioinformatics capabilities, is creating opportunities to use sequencing in multiple medical situations, including the molecular characterization of rare diseases, the individualization of treatment (particularly in cancer), pharmacogenomics, preconception/prenatal screening and population screening for disease risk. ${ }^{3,4}$ In all of these applications, there is potential for the recognition and reporting of incidental (or secondary) findings, which are results that are not related to the indication for ordering the sequencing but that may nonetheless be of medical value or utility to the ordering physician and the patient. Considerable literature discusses the utility and ethics of reporting incidental findings discovered in the course of research, ${ }^{5-9}$ but relatively little has been written about doing so in the clinical context. ${ }^{10-14}$ Last year, the American College of Medical Genetics and Genomics (ACMG) published a policy statement related to clinical sequencing ${ }^{15}$ that emphasized the importance of secondary or incidental results in pretest patient discussions, clinical testing, and reporting of results. Here, we provide the recommendations of the ACMG Working Group on Incidental Findings in Clinical Exome and Genome Sequencing (hereafter referred to as the Working Group). These recommendations have been approved by the Board of the ACMG.

\section{PROCESS}

The chairs of the Working Group were appointed in November, 2011 and a written charge to the Working Group was approved by the ACMG Board of Directors in January, 2012. The Board charged this Working Group with evaluating the utility of making recommendations for analyzing and reporting incidental findings from sequencing in the clinical context. The Working Group was asked to generate an initial list of genes and categories of variants to be reported as incidental 
findings. Working group members were appointed and approved by the ACMG Board in January, 2012 and met weekly by teleconference between January and September, 2012 and by email throughout the development of this manuscript. The Working Group began by establishing general processes for accomplishing its charge. We decided to consider both broad categories of disorders as well as specific genes. The initial list of genes considered by the Working Group was derived

from the genes evaluated in Green et al. ${ }^{10}$ and supplemented by a provisional list of genes ${ }^{13}$ being evaluated at the University of Washington for return of results.

The Working Group presented its principles and plans, and solicited feedback at an Open Forum at the ACMG Annual Meeting in March, 2012. These principles and plans were further developed based on feedback from ACMG members, and were provisionally reviewed by the ACMG Board in May, 2012 and again in November, 2012. A group of 20 additional experts was nominated by the Working Group members in May, 2012. Fifteen agreed to serve as external reviewers, and feedback from the additional reviewers was solicited in conference calls in June, 2012 and by email in January, 2013. The recommendations and this manuscript were revised based on this feedback. Final approval by the ACMG Board was provided on March 19, 2013.

The Working Group used the ACMG policy statement entitled IPoints to Consider in the Clinical Application of Genomic Sequencing ${ }^{5}$ as a starting point for its deliberations. That document includes a definition of clinical sequencing, describes the indications for such testing, and provides guidance on pre-test considerations, results reporting, genetic screening issues, and post-test considerations. Those issues were not revisited by this Working Group except to the extent that such considerations may be specifically affected by incidental findings.

\section{DEFINITIONS:}

\section{Clinician}

This term refers to the individual practitioner or clinical team who has direct contact or is responsible for direct contact with the patient and family. The clinician should be properly trained 
and prepared in genetics and genomics with an understanding of genetic counseling, pedigree analysis and risk assessment to provide pre-test and post-test patient care associated with clinical sequencing. ${ }^{15}$

\section{Laboratory}

This term refers to the entity that takes responsibility for analysis, interpretation, and report generation of sequencing performed for clinical purposes. The Working Group recognizes that in some cases, one entity may generate the raw sequencing data and another may further evaluate and interpret the sequence, consider additional or confirmatory testing and issue a clinical report. The latter is the focus of these recommendations.

\section{Patient}

This term is used to describe adults who undergo clinical sequencing and are competent to make their own health care decisions. The term, as used here, also refers to parents of minor children or guardians of decisionally-impaired adults who may undergo this testing. In cases where young children or decisionally-impaired adults undergo sequencing, pre- and post-test counseling and consent of parents or guardians on behalf of the minor or decisionally impaired adult should occur, but teenagers and mildly decisionally-impaired adults should not be excluded from these discussions and assent should be sought in appropriate cases.

\section{Primary Finding}

This term is used to describe pathogenic alterations in a gene or genes that are relevant to the diagnostic indication for which the sequencing was ordered (e.g., a mutation in MECP2 in a girl with loss of developmental milestones).

\section{Incidental Finding}

This term has been used in a variety of clinical and research contexts to indicate unexpected positive findings. Other terms have been used to describe these findings, particularly when they are sought after (rather than being unexpectedly discovered). These terms include ז̃serendipitous and iatrogenicòfindings, ${ }^{16}$ m̃on-incidental secondary findingsờ ${ }^{7}$ ñunanticipated 
findingsò ${ }^{18}$ and rofff-target resultsò ${ }^{1}$ We use ñncidental findingsòin this paper to indicate the results of a deliberate search for pathogenic or likely pathogenic alterations in genes that are not apparently relevant to a diagnostic indication for which the sequencing test was ordered.

\section{WORKING GROUP CONSIDERATIONS}

\section{The Clinical Utility of Incidental Findings}

Some have argued that incidental findings should not be reported at all in clinical sequencing until there is strong evidence of benefit, while others have advocated that variations in any and all disease-associated genes could be medically useful and should be reported. ${ }^{19}$ The Working Group acknowledged that there was insufficient evidence about benefits, risks and costs of disclosing incidental findings to make evidence-based recommendations. Nonetheless, based upon available evidence and clinical consensus among its members, the Working Group determined that reporting some incidental findings would likely have medical benefit for the patients and families of patients undergoing clinical sequencing. In reaching this consensus we recognized that our clinical experience has been derived largely from patients with disease symptoms or positive family histories. As additional evidence accrues on the penetrance of these variants among persons without symptoms or family history, these recommendations will be expected to evolve.

The Working Group elected to present recommendations in the form of a r̃minimum listòof incidental findings to report from clinical sequencing. While all of the disorders are rare, most of these genes and variant categories were selected because they are associated with the more common of the monogenic disorders, and because the Working Group reached a consensus that they met criteria described below. The Working Group specified a set of disorders, the relevant associated genes and certain categories of variants that should be reported, based on a consensus-driven assessment of clinical validity and utility. Where evidence was lacking, the 
Working Group drew upon the clinical judgment of its members. The Working Group acknowledged that its membership (and the ad hoc reviewers listed in the Appendix) were not always in complete agreement, could not fully represent the opinions of others in the field, and did not have detailed knowledge of all of the conditions that were considered.

The Working Group tried to include conditions on the list where confirmatory approaches for medical diagnosis would be available, although we recognized that this standard could not be met for all of the conditions listed. The Working Group prioritized disorders where preventative measures and/or treatments were available and disorders in which individuals with pathogenic mutations might be asymptomatic for long periods of time. In most cases, the Working Group recommended restricting the variants to be reported as incidental findings to those that meet criteria for reporting as Pathogenic (noted as î́Sequence variation is previously reported and is a recognized cause of the disorderòor rísequence variation is previously unreported and is of the type which is expected to cause the disorderò ${ }^{20}$ These were chosen because we recognized the challenge of attempting to report and interpret variants of unknown significance as incidental findings. Given the low prior probability that an individual has a monogenic disorder that could be identified incidentally through exome or genome sequencing, we recommended that only variants with a higher likelihood of causing disease should be reported as incidental findings although we recognize that there are limited data available in many cases to make this assessment.

While some definitions of incidental findings allude to findings that are discovered without actually searching for results, this was not the basis for our recommendations. The Working Group recommended that the laboratory actively search for the specified types of mutations in the specified genes listed in these recommendations.

In making these recommendations, the Working Group only addressed the circumstance in which the report of incidental findings would be delivered to the clinician who ordered the clinical sequencing. It was expected that this clinician would contextualize any incidental findings for the patient in light of personal and family history, physical examination, and other relevant findings. 
This places responsibility for managing incidental findings with the ordering clinician, as we believe that the clinician-patient interaction is the appropriate place for such information to be explained and discussed..$^{21,22}$

\section{Limitations and Interpretation of Incidental Findings}

The Working Group recognized that when a laboratory evaluates genes for the specified categories of variants recommended here as incidental findings, the analysis may not be technically equivalent to examining these genes as a primary finding. For example, sequencing could have areas of diminished or absent coverage in the genes examined for incidental findings that would be filled in by Sanger sequencing or other supplementary approaches if the gene were being evaluated for a primary indication. In addition, while genome sequencing can provide increasingly reliable information on copy number variation and translocations, exome sequencing is currently less reliable, and neither technology can be used to measure tandem repeat size accurately. For these reasons, we did not include some disorders where structural variants (e.g., translocations and inversions), repeat expansions, or copy number variations are the primary cause, and have not recommended that laboratories utilize orthogonal techniques to search for these variants in the genes named in the minimum list. Thus, the Working Group recommended that laboratories evaluate these genes for the specified categories of variants to the extent that the available data from the genome or exome sequence allow. We did not recommend that labs insure a depth of coverage for these genes equivalent to molecular testing for a primary indication. Given these recommendations, the Working Group was concerned that a negative incidental findings report could be misconstrued by clinicians or patients as an assurance of the absence of a pathogenic variant, which is not always the case. To address this, we recommended that the report of incidental findings issued by the laboratory include distinct language differentiating the quality of the incidental findings report from the quality of molecular testing that would be conducted for a primary indication. 
On the other hand, when there is a positive incidental finding, the Working Group recommended that laboratories review available literature and databases at the time of the sequence interpretation to insure there is sufficient support for pathogenicity before reporting a variant. The Working Group recognized that there is no single database currently available that represents an accurately curated compendium of known pathogenic variants, nor is there an automated algorithm to identify all novel variants meeting criteria for pathogenicity. Therefore, evaluation and reporting of positive findings in these genes may require significant manual curation.

\section{Patient Preferences and Incidental Findings}

Standards for molecular testing in clinical genetics have largely evolved around testing an affected individual or suspected carrier for a mutation or testing an unaffected relative of a patient with a known mutation. In these situations, extensive pre-test counseling can ascertain with confidence the preference of the individual to be tested in terms of choosing whether or not to obtain a specific genetic test for a specific hereditary condition. By contrast, after clinical sequencing for a specific indication, the patient has already undergone an assay of all other disease-associated genes. In order to respect preferences in the same manner as with targeted testing, the patient whose exome or genome is sequenced would have to undergo an extensive, and possibly overwhelming, amount of genetic counseling for numerous conditions unrelated to the primary indication for sequencing. This will become impractical as clinical sequencing becomes more common and both its lack of standardization and its application to patients of all circumstance might result in deeply varying levels of truly informed preference setting.

Even if preferences about receiving a limited set of incidental findings were accurately explained, carefully noted and clearly communicated to the laboratory, the laboratory would have to mask the informatics analysis of specific genes or ignore findings of potential medical importance in order to honor those preferences. All of this may be feasible in an environment 
where the laboratory is an interactive partner in the clinical assessment of a patient by clinicians skilled in genetics and genetic counseling, but will become increasingly unwieldy as clinical sequencing becomes more common and more commonly ordered by clinicians with varying levels of ability and experience in genetic counseling. Based upon these considerations, the Working Group did not favor offering the patient a preference as to whether or not to receive the minimum list of incidental findings described in these recommendations. We recognize that this may be seen to violate existing ethical norms regarding the patient $\hat{\Phi}$ autonomy and r̃ight not to knowògenetic risk information. However, in selecting a minimal list that is weighted toward conditions where prevalence may be high and intervention may be possible, we felt that clinicians and laboratory personnel have a fiduciary duty to prevent harm by warning patients and their families about certain incidental findings and that this principle supersedes concerns about autonomy, just as it does in the reporting of incidental findings elsewhere in medical practice. The Working Group therefore recommended that whenever clinical sequencing is ordered, the ordering clinician should discuss with the patient the possibility of incidental findings, and that laboratories seek and report findings from the list described in the Table without reference to patient preferences. Patients have the right to decline clinical sequencing if they judge the risks of possible discovery of incidental findings to outweigh the benefits of testing.

\section{Incidental Findings in Children}

The standards for predictive genetic testing in clinical genetics recognize a distinction between providing results to adults and providing results to children and adolescents, with consistent recommendations that predictive testing for adult-onset diseases not be offered to children. ${ }^{23-25}$ However, these recommendations can be inconsistent with the general practice of respecting parental decision-making about their children $\hat{\mathbf{s}}$ health, and questions have been raised about the sustainability of these standards in an era of comprehensive genomic testing. ${ }^{26}$ One of these recent policy statements noted ré results from genetic testing of a child may have 
implications for the parents and other family members. Health care providers have an obligation to inform parents and the child, when appropriate, about these potential implications. $\sigma^{4}$ This statement suggests an important consideration in the era of genomic medicine since after sequencing a child for a primary indication, it becomes relatively easy for a laboratory to report a limited number of variants for conditions that could be medically important to that child $\hat{\Phi}$ future or to the rest of the family.

The Working Group recognized that this is a transitional moment in the adaptation of genomic medicine where the parents of children undergoing sequencing do not have ready access to inexpensive, readily interpretable exome or genome sequencing in order to obtain personal risk information for the conditions on our minimum list. In the future, where parents might all have such access, the identification of an adult-onset disease variants in their children could be restricted. But at this moment in the evolution of clinical sequencing, an incidental finding relevant to adult disease that is discovered and reported through clinical sequencing of a child may be the only way in which that variant will come to light for the parent. As with the argument against preferences, the Working Group felt that masking or tailoring the reporting of such information according to the age of the patient could place an unrealistic burden upon laboratories facing increasing volumes of clinical sequencing. The Working Group also felt that the ethical concerns about providing children with genetic risk information about adult-onset diseases were outweighed by the potential benefit to the future health of the child and the child $\hat{\mathbf{S}}$ parent of discovering an incidental finding where intervention might be possible. Therefore, the Working Group recommended that recommendations for seeking and reporting incidental findings not be limited by the age of the person being sequenced.

\section{Circumstances Not Addressed in these Recommendations}

The Working Group elected not to address a number of issues related to incidental findings in clinical sequencing. Conditions that were part of routine newborn screening (NBS) were 
excluded as they have their own assessment criteria and are applied in a specific public health framework. Similarly, these recommendations address incidental findings sought and reported during clinical sequencing for a specific clinical indication but do not address preconception sequencing, prenatal sequencing, newborn sequencing or sequencing of healthy children and adults. In particular, the issues associated with genomic sequencing in healthy individuals of any age will become increasingly salient as costs decline and informatics interpretation algorithms improve, but the value of population screening for prevention and health promotion raises complex questions of potential benefits as well as downstream risks and costs that will need considerably more data to resolve. ${ }^{27-30}$ We acknowledged but did not address the possibility that clinical sequencing may be ordered by specialists who may not feel comfortable discussing incidental findings pertaining to another organ system, thus generating additional consultations and medical costs. We elected not to consider questions of data ownership or the legal ramifications of returning or withholding raw sequencing results from families that request these. We also did not address issues of patents in making these recommendations or any of the issues associated with duty to recontact ordering clinicians (or patients) and update the interpretation of their incidental findings. ${ }^{31}$ We have not addressed the implications of including incidental findings in laboratory reports that will become part of the patient $\hat{\mathbf{s}}$ health record and the potential for discrimination that could arise from this circumstance. We recognize that laboratories that adopt these recommendations may add significant costs to at least some of their sequencing reports with primer design and Sanger confirmation of positive findings, evidence review, report generation and sign-out. We do not know the implications that this may have on reimbursement for clinical sequencing.

There is an active debate about the return of incidental findings in genomic research, and recommendations for this setting are evolving. While we acknowledge and hope that investigators find our process and these recommendations useful in their attempts to design thresholds and lists for the return of genomic findings to research participants, we did not design this list for that 
purpose. The Working Group has designed these recommendations for the situation in which a clinician orders exome or genome sequencing for a specific clinical indication. In this circumstance, a laboratory report will be returned to that clinician, who will ideally be in a position to integrate such findings with the medical and family history and the physical examination, taking into account the psychological state of the patient and the patient $\hat{\Phi}$ family. While we recognize that this ideal may not always be realized, this is nonetheless a very different scenario than the disclosure of sequence information outside of the medical care system. The return of incidental findings discovered in the course of a clinical laboratory investigation is consistent with such practices in other disciplines of medicine.

\section{RECOMMENDATIONS}

1. Constitutional mutations found in the genes on the minimum list (see Table) should be reported by the laboratory, regardless of the indication for which the clinical sequencing was ordered.

a. Additional genes may be analyzed for incidental (secondary) variants, as deemed appropriate by the laboratory.

b. Incidental (secondary) variants should be reported regardless of the age of the patient.

c. Incidental (secondary) variants should be reported for any clinical sequencing conducted on a constitutional (but not tumor) tissue. This includes the normal sample of a tumor-normal sequenced dyad and unaffected members of a family trio.

2. The Working Group recommends that laboratories seek and report only the types of variants within these genes that we have delineated (see Table).

a. For most genes, only variants that have been previously reported and are a recognized cause of the disorder or variants that are previously unreported but are 
of the type which is expected to cause the disorder, as defined by prior ACMG guidelines, ${ }^{20}$ should be reported.

b. For some genes, predicted loss of function variants are not relevant (e.g., COL3A1 and most hypertrophic cardiomyopathy genes).

c. For some genes (e.g., APOB), laboratories should only report variants for certain conditions.

3. It is the responsibility of the ordering clinician/team to provide comprehensive pre-and posttest counseling to the patient.

a. Clinicians should be familiar with the basic attributes and limitations of clinical sequencing.

b. Clinicians should alert patients to the possibility that clinical sequencing may generate incidental findings that could require further evaluation.

c. Given the complexity of genomic information, the clinical geneticist should be consulted at the appropriate time that may include ordering, interpreting, and communicating genomic testing.

4. These recommendations reflect limitations of current technology, and are therefore focused on disorders that are caused by point mutations and small insertions and deletions, not those primarily caused by structural variants, repeat expansions, or copy number variations.

5. The Working Group recommends that the ACMG, together with content experts and other professional organizations, refine and update this list at least annually.

\section{DISCUSSION}

The ACMG recommends that for any evaluation of clinical sequencing results, all of the genes and types of variants in the Table should be examined and the results reported to the ordering clinician. The conditions listed in the Table are those that the Working Group and external 
reviewers considered most likely to be verifiable by other diagnostic methods and amenable to medical intervention based on current evidence and the clinical consensus of the Working Group members. Reporting these incidental findings to the ordering clinician will offer the clinician, or an appropriate consulting clinician, the opportunity to re-evaluate the patientês personal and family history and consider appropriate surveillance or intervention for patients and their family members who are deemed to be at increased risk for these conditions. These recommendations should be understood to represent a minimum list that is a starting point for the selection and reporting of incidental findings, fully acknowledging that as additional evidence and expertise are applied, these recommendations will require ongoing modification. The ACMG recognizes that laboratories may need to take some time to implement these recommendations.

For most of the recommended genes, only variants that have been previously reported and are a recognized cause of the disorder or variants that are previously unreported and are of the type which is expected to cause the disorder have been recommended for analysis and reporting, and an argument could be made for the examination and reporting of a broader range of novel variation predicted informatically to be of possible significance. However, because informatics tools are still unreliable predictors of variant impact, particularly for missense variants, and because incidental findings are, by definition, identified in persons outside of the clinical indication for testing, these patients are at a low prior probability of being affected by the conditions in the Table. The conditions and variant thresholds we selected for reporting incidental findings have therefore been set to try to maximize the benefits (increasing the likelihood of true positive results) and minimize the harms (decreasing the likelihood of false positive results).

There is concern that incidental variant reporting could be misinterpreted as an exhaustive evaluation of all variation within the genes on this list. These recommendations should not be construed as an expectation that the laboratory comprehensively assess these genes for all variants, but rather that the laboratory evaluate the sequence data on these genes that are generated in the course of routine clinical sequencing. There is potential for confusion and even 
harm to patients if the clinician misunderstands these limitations of the incidental findings report. For example, if incidental findings are returned without identification of mutations for any of the cancer susceptibility syndromes, and it later comes to light that the patient has a family history suggestive of a Mendelian cancer susceptibility syndrome, the patient or other family members might incorrectly consider themselves to have been f̃estedòand found to be m̃egative.òln fact, a novel missense mutation that may or may not be causative of the disorder, could be segregating with affected family members may (appropriately) not have been included in the report of incidental findings. An analogous situation has been noted with false negative findings in newborn screening. ${ }^{32}$ To insure that these considerations are properly presented to the clinicians, we recommend that laboratories develop an appropriate reporting metric that will make clear the extent of the evaluation that has been conducted. This will allow clinicians to consider the sensitivity of the analysis when making clinical assessments and will help avoid over-interpretation of a negative incidental (secondary) variant analysis.

All of these considerations should be incorporated into an incidental or secondary results report that provides clinicians with a clear summary of the analysis that was performed, the depth of coverage and other quality metrics, and any findings. We estimate from limited amount of published data ${ }^{33}$ that approximately $1 \%$ of sequencing reports will include an incidental variant from the Table. As recommended in the ACMG policy statement on clinical sequencing, the clinician ordering these tests is responsible for providing or ensuring the provision of pretest counseling so that the patient is aware of not only the implications and limitations of the primary testing, but also the analysis that is being performed for incidental findings. The clinician should also provide posttest counseling and medical follow-up as described in the prior ACMG policy statement on Clinical Application of Genomic Sequencing. ${ }^{15}$ The informed consent process for clinical sequencing should follow the forthcoming guideline from the ACMG.

The return of incidental findings to parents of minor children who undergo clinical sequencing presents difficult issues. The Working Group felt it best not to place arbitrary age 
restrictions or limitations on the return of incidental (secondary) variants since the variants would likely have implications for others in the family. For example, the sequencing of a child and the discovery of incidental findings that increase the risk of adult-onset cancer predisposition may be medically important to one of the parents of that child. In this scenario, the result has been generated and is fully available. To mask or withhold the incidental finding is to state that the

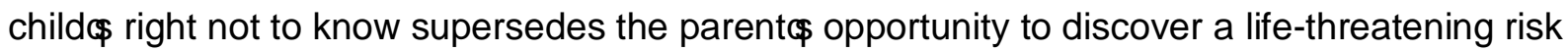
factor. We recognize that this recommendation differs from those developed around candidate gene testing. There are legitimate concerns about whether pediatricians should be asked to receive and manage results pertaining to adult-onset conditions and about the psychological impact of such information on the family. We further acknowledge that there are groups proposing to avoid this issue when sequencing children by sophisticated masking of off-target genes, making them unavailable for evaluation. ${ }^{34}$ Nonetheless, we believe that sequencing creates a different calculus than that which was envisioned with predictive testing for a familial condition. In the absence of clarifying data about the actual harms of learning about adult-onset conditions in children, or the actual benefits to parents who might learn previously unsuspected risk information through sequencing of their child, we have recommended disclosure of the conditions, genes and variants listed in the Table for both adults and children who undergo clinical sequencing.

The Working Group recognizes that there is a wide range of opinions about what constitutes incidental findings in clinical sequencing and how they should be managed. On one side are genetic libertarians who feel that patients have the right to full and complete accounting of all possible risks conveyed by both established and novel variants, or even variants of unknown significance in disease genes. On the other side are genetic empiricists who believe that there is insufficient evidence about the penetrance of most pathogenic variants in the general population to warrant the sharing of any incidental findings, and that it is irresponsible to create the psychological burdens of being a ñpatient in waiting ${ }^{35}$ or to expose patients to iatrogenic harm of possibly unnecessary surveillance or diagnostic testing. An argument is sometimes made that if the search 
for incidental findings were warranted, then it would follow that broad-based population screening should be advocated. In reality, seeking and reporting of incidental findings represents a form of

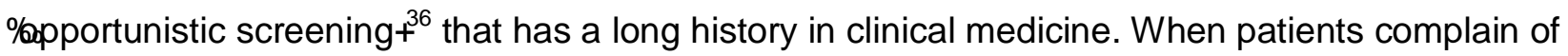
symptoms in the digestive system, the well-trained physician examines cardiac and respiratory systems as well, both for clues to a multi-system disease and to incidentally discover any unrelated signs. When radiographs are read for a particular anatomical focus, the radiologist scans the entire radiograph and also reports on abnormal findings in regions not indicated as the primary reason for the study. In these situations, unlike population screening with its requirement of extensive cost and infrastructure, the patient has already presented to the medical care system, has been evaluated and is under the care of a clinician. Moreover, much of the cost of the study and any associated risk has already been sustained for the primary indication, lowering the cost/risk-tobenefit ratio for the discovery of incidental findings.

The Working Group recognizes that many of the concerns, debates, and widely varying opinions described here are the consequence of a lack of empiric data. We recognize this critical limitation, but nonetheless determined that an initial set of recommendations was appropriate at this time. To address the issue of a lack of data, the Working Group encourages prospective research on incidental or secondary findings and the development of a voluntary national patient registry to longitudinally follow individuals and their families who receive incidental or secondary findings as part of clinical sequencing and document the benefits, harms and costs that may result.

In summary, the Working Group has recommended that when a report is issued for clinically indicated exome and genome sequencing, a minimum list of conditions, genes and variants should be routinely evaluated and reported to the ordering clinician who can place them

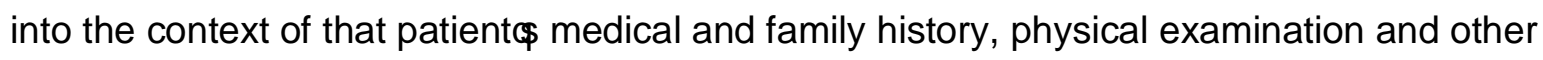
laboratory testing. We have recommended that these findings be reported without seeking preferences from the patient and family and without limitation due to the patient $\hat{\Phi}$ age. In this, we attempt to strike a balance between the positions of genetic libertarians and the genetic 
empiricists, guided by the currently available scientific literature, clinical experience, the consensus of our Working Group members and the traditions of clinical medicine. The Working Group recognizes that this list should, and will, evolve as further empirical data are collected on the actual penetrance of these variants, and on the health benefits and costs that might follow from their disclosure as incidental findings.

\section{DISCLOSURES}

LGB, JSB, WWG, CLM, AM, RLM, KEO, and HLR have grants related to genome sequencing LGB receives in kind research support from the Illumina Corp.

JSB and HLR are uncompensated members of Advisory Board members for Complete Genomics. BRK, HLR, and MSWi are involved with clinical laboratories offering genome sequencing services. AM, RLN, and JMO own stock in genome sequencing companies.

RLN provides compensated consulting to Complete Genomics.

JOD was employed by Illumina Corp. during the development of these recommendations

\section{ACKNOWLEDGMENTS}

Conflicts of Interest/Funding Support: Members of the ACMG Working Group on Secondary Findings in Exome and Genome Sequencing were all reviewed for conflicts of interest by the Board of the ACMG. Research funding from the following sources supported efforts by members of this Working Group: HG006500 (Green, Rehm, Maguire); HG005092, HG003178, HG00603, HG006615, HG003170, GM007748, AG027841, CA154517 (Green); HG003389 (Ormond); HG006382 (Williams); HG006500, HG006485, HG006612 (Maguire); ES017793, DK087728, Michael J. Fox Foundation, National Parkinson Disease Foundation and DOD W81XWH-12-10569 (Nussbaum); HG004488, RR025747, RR025746, RR025745, HG006487, UNC Cancer Research Fund, UNC Bryson Philanthropic Fund, and the UNC Center for Genomics and Society (Berg). Dr. Biesecker is supported by the Intramural Research Program of the National Human Genome Research Institute. 
We thank the following individuals for their review and comments on drafts of this paper, many of which were adopted by the Working Group. Margaret Adam, Jeffrey Botkin, Wendy Chung, David Dimmock, Christine Eng, Madhuri Hegde, Gail Jarvik, Stephen Kingsmore, Michael Murray, Katherine Nathanson, Sharon Plon, Reed Pyeritz, Cheryl Reid, V. Reid Sutton, Benjamin Wilfond. The final version of this paper and its recommendations do not necessarily reflect the views of these individuals. 


\section{REFERENCES}

1. Mayer AN, Dimmock DP, Arca MJ, et al. A timely arrival for genomic medicine. Genetics in Medicine. Mar 2011;13(3):195-196.

2. Manolio TA, Chisholm RL, Ozenberger B, et al. Implementing genomic medicine in the clinic: The future is here. Genetics in Medicine. 2013.

3. Biesecker LG. Opportunities and challenges for the integration of massively parallel genomic sequencing into clinical practice: Lessons from the ClinSeq project. Genetics in Medicine. Apr 2012;14(4):393-398.

4. Green R, Rehm HL, Kohane I. Clinical genome sequencing. In: Ginsburg G, Willard $\mathrm{H}$, eds. Genomic and Personalized Medicine. Vol in press. San Diego: Elsevier; 2013.

5. Wolf SM, Crock BN, Van Ness B, et al. Managing incidental findings and research results in genomic research involving biobanks and archived datasets. Genetics in Medicine. 2012;14(4):361-384.

6. Knoppers BM, Deschenes M, Zawati MH, Tasse AM. Populations studies: Return of research results and incidental findings Policy Statement. European Journal of Human Genetics. 2012. doi:10.1038/ejhg.2012.152.

7. Fullerton SM, Wolf WA, Brothers KB, et al. Return of individual research results from genome-wide association studies: Experience of the Electronic Medical Records and Genomics (eMERGE) Network. Genetics in Medicine. Apr 2012;14(4):424-431.

8. Simon CM, Williams JK, Shinkunas L, Brandt D, Daack-Hirsch S, Driessnack M. Informed consent and genomic incidental findings: IRB chair perspectives. Journal of Empirical Research on Human Research Ethics. 2011;6:53-67.

9. Van Ness B. Genomic research and incidental findings. Journal of Law, Medicine, \& Ethics. Summer 2008;36(2):292-297, 212.

10. Green RC, Berg JS, Berry GT, et al. Exploring concordance and discordance for return of incidental findings from clinical sequencing. Genetics in Medicine. Apr 2012;14(4):405-410.

11. Berg JS, Khoury MJ, Evans JP. Deploying whole genome sequencing in clinical practice and public health: Meeting the challenge one bin at a time. Genetics in Medicine. Jun 2011;13(6):499-504.

12. Kohane IS, Hsing M, Kong SW. Taxonomizing, sizing, and overcoming the incidentalome. Genetics in Medicine. 2012;14(4):399-404.

13. Berg J, Adams M, Nassar N, et al. An informatics approach to analyzing the incidentalome. Genetics in Medicine. 2012;15:36-44. 
14. Lohn Z, Adam S, Birch P, Townsend A, Friedman J. Genetics professionals' perspectives on reporting incidental findings from clinical genome-wide sequencing. American Journal of Medical Genetics Part A. Mar 2013;161(3):542-549.

15. American College of Medical Genetics and Genomics. Points to consider in the clinical application of genomic sequencing. Genetics in Medicine. Aug 2012;14(8):759-761.

16. Westbrook JI, Braithwaite J, Mclntosh JH. The outcomes for patients with incidental lesions: Serendipitous or iatrogenic? American Journal of Roentgenology. Nov 1998;171(5):1193-1196.

17. Anastasova V, Blasimme A, Julia S, Cambon-Thomsen A. Genomic incidental findings: Reducing the burden to be fair. The American Journal of Bioethics. 2013;13(2):52-54.

18. Parker LS. The future of incidental findings: Should they be viewed as benefits? Journal of Law, Medicine, \& Ethics. Summer 2008;36(2):341-351.

19. Angrist M. You never call, you never write: Why return of 'omic' results to research participants is both a good idea and a moral imperative. Personalized Medicine. 2011;8:651-657.

20. Richards CS, Bale S, Bellissimo DB, et al. ACMG recommendations for standards for interpretation and reporting of sequence variations: Revisions 2007. Genetics in Medicine. Apr 2008;10(4):294-300.

21. Beskow L, Burke W. Offering individual genetic research results: Context matters. Science Translational Medicine. Jun 30 2010;2(38):20-38.

22. Costain G, Bassett AS. Incomplete knowledge of the clinical context as a barrier to interpreting incidental genetic research findings. The American Journal of Bioethics. Feb 2013;13(2):58-60.

23. American Society of Human Genetics Board of Directors and American College of Medical Genetics Board of Directors. Points to consider: Ethical, legal, and psychosocial implications of genetic testings in children and adolescents. American Journal of Human Genetics. 1995;57:1233-1241.

24. Committee on Bioethics. Ethical and policy issues in genetic testing and screening of children. Pediatrics. 2013. doi: 10.1542/peds.2012-3680.

25. Ross LF, Saal HM, David KL, Anderson RR. Technical report: Ethical and policy issues in genetic testing and screening of children. Genetics in Medicine. Feb 21 2013. doi:10.1038/gim.2012.176.

26. Wilfond B, Ross LF. From genetics to genomics: Ethics, policy, and parental decision-making. Journal of Pediatric Psychology. Jul 2009;34(6):639-647.

27. Morrison AS. Screening in Chronic Disease. New York: Oxford University Press; 1985. 
28. Khoury MJ, McCabe LL, McCabe RB. Population screening in the age of genomic medicine. New England Journal of Medicine. 2003;348:50-58.

29. Khoury M, Berg A, Coates R, Evans J, Teutsch S, Bradley L. The evidence dilemma in genomic medicine. Health Affairs. 2008;27(6):1600-1611.

30. Khoury M. Public health genomics: The end of the beginning. Genetics In Medicine. 2011 Mar 2011;13(3):206-209.

31. Pyeritz RE. The coming explosion in genetic testing--is there a duty to recontact? New England Journal of Medicine. Oct 13 2011;365(15):1367-1369.

32. Fritz A. Estimating the annual number of false negative cystic fibrosis newborn screening tests. Pediatric Pulmonology. 2012;47:207-208.

33. Johnston JJ, Rubinstein WS, Facio FM, et al. Secondary variants in individuals undergoing exome sequencing: Screening of 572 individuals identifies highpenetrance mutations in cancer-susceptibility genes. American Journal of Human Genetics. Jul 13 2012;91(1):97-108.

34. Saunders CJ, Miller NA, Soden SE, et al. Rapid whole-genome sequencing for genetic disease diagnosis in neonatal intensive care units. Science Translational Medicine. Oct 3 2012;4(154):135-154.

35. Kwon JM, Steiner RD. "I'm fine; I'm just waiting for my disease": The new and growing class of presymptomatic patients. Neurology. 2011;77:522-523.

36. Wright $\mathrm{C}$, Burton $\mathrm{H}$, Hall A, et al. Next steps in the sequence. The implications of whole genome sequencing for health in the UK2011. 978-1-907198-08-3. 


\section{TABLE}

\begin{tabular}{|c|c|c|c|c|c|c|c|}
\hline Phenotype & $\begin{array}{c}\text { MIM - } \\
\text { Disorder }\end{array}$ & $\begin{array}{c}\text { PMID - } \\
\text { GeneReviews } \\
\text { Entry }\end{array}$ & $\begin{array}{l}\text { Age of } \\
\text { Onset }\end{array}$ & Gene & $\begin{array}{l}\text { MIM - } \\
\text { Gene }\end{array}$ & Inheritance* & $\begin{array}{l}\text { Variants to } \\
\text { Report }\end{array}$ \\
\hline \multirow{2}{*}{$\begin{array}{l}\text { Hereditary Breast and } \\
\text { Ovarian Cancer }\end{array}$} & \multirow{2}{*}{$\begin{array}{l}604370 \\
612555\end{array}$} & \multirow{2}{*}{20301425} & \multirow{2}{*}{ Adult } & $B R C A 1$ & 113705 & \multirow{2}{*}{$A D$} & \multirow{2}{*}{$\mathrm{KP} \& \mathrm{EP}$} \\
\hline & & & & BRCA2 & 600185 & & \\
\hline Li-Fraumeni Syndrome & 151623 & 20301488 & Child/adult & TP53 & 191170 & $A D$ & KP \& EP \\
\hline $\begin{array}{l}\text { Peutz-Jeghers } \\
\text { Syndrome }\end{array}$ & 175200 & 20301443 & Child/adult & STK11 & 602216 & $A D$ & $\mathrm{KP} \& \mathrm{EP}$ \\
\hline \multirow{5}{*}{ Lynch Syndrome } & \multirow{5}{*}{120435} & \multirow{5}{*}{20301390} & \multirow{5}{*}{ Adult } & MLH1 & 120436 & \multirow{5}{*}{$A D$} & \multirow{5}{*}{$\mathrm{KP} \& \mathrm{EP}$} \\
\hline & & & & MSH2 & 609309 & & \\
\hline & & & & & & & \\
\hline & & & & MSH6 & 600678 & & \\
\hline & & & & PMS2 & 600259 & & \\
\hline $\begin{array}{c}\text { Familial adenomatous } \\
\text { polyposis }\end{array}$ & 175100 & 20301519 & Child & $A P C$ & 611731 & $A D$ & $\mathrm{KP} \& \mathrm{EP}$ \\
\hline $\begin{array}{c}\text { MYH-Associated } \\
\text { Polyposis; Adenomas, } \\
\text { multiple colorectal, FAP } \\
\text { type 2; Colorectal } \\
\text { adenomatous polyposis, } \\
\text { autosomal recessive, } \\
\text { with pilomatricomas }\end{array}$ & $\begin{array}{l}608456 \\
132600\end{array}$ & 23035301 & Adult & MUTYH & 604933 & $\mathrm{AR}^{\star *}$ & $\mathrm{KP} \& \mathrm{EP}$ \\
\hline $\begin{array}{l}\text { Von Hippel Lindau } \\
\text { syndrome }\end{array}$ & 193300 & 20301636 & Child/adult & $V H L$ & 608537 & $A D$ & $\mathrm{KP} \& \mathrm{EP}$ \\
\hline
\end{tabular}




\begin{tabular}{|c|c|c|c|c|c|c|c|}
\hline $\begin{array}{l}\text { Multiple Endocrine } \\
\text { Neoplasia Type } 1\end{array}$ & 131100 & 20301710 & Child/adult & MEN1 & 613733 & $A D$ & $K P \& E P$ \\
\hline $\begin{array}{l}\text { Multiple Endocrine } \\
\text { Neoplasia Type } 2\end{array}$ & $\begin{array}{l}171400 \\
162300\end{array}$ & 20301434 & Child/adult & RET & 164761 & $A D$ & $\mathrm{KP}$ \\
\hline \multirow[b]{2}{*}{$\begin{array}{c}\text { Familial Medullary } \\
\text { Thyroid Cancer (FMTC) }\end{array}$} & \multirow[b]{2}{*}{1552401} & \multirow[b]{2}{*}{20301434} & \multirow[b]{2}{*}{ Child/adult } & RET & 164761 & $\mathrm{AD}$ & \multirow[b]{2}{*}{$\mathrm{KP}$} \\
\hline & & & & NTRK1 & 191315 & $\begin{array}{l}\text { Suspected } \\
\text { AD }\end{array}$ & \\
\hline $\begin{array}{l}\text { PTEN Hamartoma } \\
\text { Tumor Syndrome }\end{array}$ & 153480 & 20301661 & Child & PTEN & 601728 & $A D$ & $K P \& E P$ \\
\hline Retinoblastoma & 180200 & 20301625 & Child & $R B 1$ & 614041 & $\mathrm{AD}$ & $\mathrm{KP} \& \mathrm{EP}$ \\
\hline \multirow{5}{*}{$\begin{array}{c}\text { Hereditary } \\
\text { Paraganglioma- } \\
\text { Pheochromocytoma } \\
\text { Syndrome }\end{array}$} & $\begin{array}{l}168000 \\
\text { (PGL1) }\end{array}$ & \multirow{5}{*}{20301715} & \multirow{5}{*}{ Child/adult } & $S D H D$ & 602690 & \multirow{5}{*}{$A D$} & $K P \& E P$ \\
\hline & $\begin{array}{l}601650 \\
\text { (PGL2) }\end{array}$ & & & SDHAF2 & 613019 & & $\mathrm{KP}$ \\
\hline & $\begin{array}{l}605373 \\
\text { (PGL3) }\end{array}$ & & & $S D H C$ & 602413 & & \multirow{3}{*}{$K P \& E P$} \\
\hline & & & & & & & \\
\hline & $\begin{array}{l}115310 \\
\text { (PGL4) }\end{array}$ & & & $S D H B$ & 185470 & & \\
\hline \multirow{2}{*}{$\begin{array}{c}\text { Tuberous Sclerosis } \\
\text { Complex }\end{array}$} & \multirow{2}{*}{$\begin{array}{l}191100 \\
613254\end{array}$} & \multirow{2}{*}{20301399} & \multirow{2}{*}{ Child } & TSC1 & 605284 & \multirow{2}{*}{$A D$} & \multirow{2}{*}{$\mathrm{KP} \& \mathrm{EP}$} \\
\hline & & & & TSC2 & 191092 & & \\
\hline WT1-related Wilms & 194070 & 20301471 & Child & WT1 & 607102 & $\mathrm{AD}$ & KP \& EP \\
\hline
\end{tabular}




\begin{tabular}{|c|c|c|c|c|c|c|c|}
\hline tumor & & & & & & & \\
\hline Neurofibromatosis type 2 & 101100 & 20301380 & Child/adult & NF2 & 607379 & $A D$ & $\mathrm{KP} \& \mathrm{EP}$ \\
\hline EDS - vascular type & 130050 & 20301667 & Child/adult & COL3A1 & 120180 & $A D$ & KP \& EP \\
\hline \multirow{7}{*}{$\begin{array}{l}\text { Marfan Syndrome, } \\
\text { Loeys-Dietz Syndromes, } \\
\text { and Familial Thoracic } \\
\text { Aortic Aneurysms and } \\
\text { Dissections }\end{array}$} & \multirow{7}{*}{$\begin{array}{l}154700, \\
609192, \\
608967, \\
610168, \\
610380, \\
613795, \\
611788\end{array}$} & \multirow{7}{*}{$\begin{array}{l}20301510 \\
20301312 \\
20301299\end{array}$} & \multirow{7}{*}{ Child/adult } & FBN1 & 134797 & \multirow{7}{*}{$A D$} & \multirow{7}{*}{$\mathrm{KP} \& \mathrm{EP}$} \\
\hline & & & & TGFBR1 & 190181 & & \\
\hline & & & & TGFBR2 & 190182 & & \\
\hline & & & & SMAD3 & 603109 & & \\
\hline & & & & ACTA2 & 102620 & & \\
\hline & & & & MYLK & 600922 & & \\
\hline & & & & MYH11 & 160745 & & \\
\hline \multirow{8}{*}{$\begin{array}{c}\text { Hypertrophic } \\
\text { cardiomyopathy, } \\
\text { Dilated cardiomyopathy }\end{array}$} & & \multirow{8}{*}{20301725} & \multirow{8}{*}{ Child/adult } & MYBPC3 & 600958 & \multirow{8}{*}{$A D$} & $\mathrm{KP} \& \mathrm{EP}$ \\
\hline & $\begin{array}{l}115197, \\
192600, \\
601494\end{array}$ & & & MYH7 & 160760 & & KP \\
\hline & 613690 & & & TNNT2 & 191045 & & $\mathrm{KP} \& \mathrm{EP}$ \\
\hline & $\begin{array}{l}115196, \\
608751,\end{array}$ & & & TNNI3 & 191044 & & \multirow{5}{*}{$\mathrm{KP}$} \\
\hline & $\begin{array}{l}612098 \\
600858\end{array}$ & & & TPM1 & 191010 & & \\
\hline & $\begin{array}{l}301500 \\
608758\end{array}$ & & & MYL3 & 160790 & & \\
\hline & \multirow{2}{*}{115200} & & & ACTC1 & 102540 & & \\
\hline & & & & PRKAG2 & 602743 & & \\
\hline
\end{tabular}




\begin{tabular}{|c|c|c|c|c|c|c|c|}
\hline & & & & GLA & 300644 & $X L$ & $\begin{array}{l}\text { KP \& EP } \\
\text { (hemi, het, } \\
\text { hom) }\end{array}$ \\
\hline & & & & MYL2 & 160781 & \multirow{2}{*}{$A D$} & $\mathrm{KP}$ \\
\hline & & & & LMNA & 150330 & & KP \& EP \\
\hline $\begin{array}{c}\text { Catecholaminergic } \\
\text { polymorphic ventricular } \\
\text { tachycardia }\end{array}$ & 604772 & & & RYR2 & 180902 & $A D$ & KP \\
\hline \multirow{5}{*}{$\begin{array}{l}\text { Arrhythmogenic right } \\
\text { ventricular } \\
\text { cardiomyopathy }\end{array}$} & & & & PKP2 & 602861 & \multirow{5}{*}{$A D$} & \\
\hline & $\begin{array}{l}609040 \\
604400\end{array}$ & & & $D S P$ & 125647 & & $\mathrm{KP} \& \mathrm{EP}$ \\
\hline & $\begin{array}{l}610476, \\
607450\end{array}$ & 20301310 & Child/adult & DSC2 & 125645 & & \\
\hline & 610193 & & & TMEM43 & 612048 & & $\mathrm{KP}$ \\
\hline & & & & DSG2 & 125671 & & KP \& EP \\
\hline \multirow{3}{*}{$\begin{array}{l}\text { Romano-Ward Long QT } \\
\text { Syndromes Types 1, 2, } \\
\text { and 3, Brugada } \\
\text { Syndrome }\end{array}$} & \multirow{3}{*}{$\begin{array}{l}192500 \\
613688, \\
603830 \\
601144\end{array}$} & \multirow{3}{*}{20301308} & \multirow{3}{*}{ Child/adult } & KCNQ1 & 607542 & \multirow{3}{*}{$A D$} & \multirow{3}{*}{$K P \& E P$} \\
\hline & & & & KCNH2 & 152427 & & \\
\hline & & & & SCN5A & 600163 & & \\
\hline \multirow{3}{*}{$\begin{array}{c}\text { Familial } \\
\text { hypercholesterolemia }\end{array}$} & \multirow{3}{*}{$\begin{array}{l}143890 \\
603776\end{array}$} & \multirow{3}{*}{$\begin{array}{l}\text { No } \\
\text { GeneReviews } \\
\text { entry }\end{array}$} & \multirow{3}{*}{ Child } & $\angle D L R$ & 606945 & SD & KP \& EP \\
\hline & & & & $A P O B$ & 107730 & SD & \multirow{2}{*}{$\mathrm{KP}$} \\
\hline & & & & PCSK9 & 607786 & $A D$ & \\
\hline
\end{tabular}




\begin{tabular}{|c|c|c|c|c|c|c|c|}
\hline $\begin{array}{l}\text { Malignant hyperthermia } \\
\text { susceptibility }\end{array}$ & 145600 & 20301325 & Child/adult & $\begin{array}{c}\text { RYR1 } \\
\text { CACNA1S }\end{array}$ & $\begin{array}{r}180901 \\
114208\end{array}$ & $A D$ & $\mathrm{KP}$ \\
\hline
\end{tabular}

- Some conditions that may demonstrate semi-dominant inheritance have been indicated as autosomal dominant (AD) for the sake of simplicity.

** Although carriers may have modestly increased risk, we recommend only searching for individuals with bi-allelic mutations.

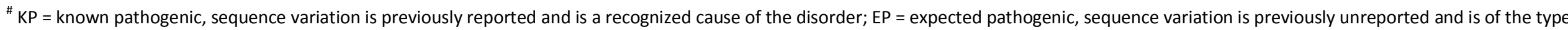

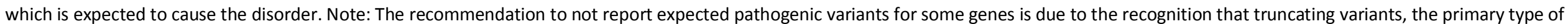
expected pathogenic variants, are not an established cause of some diseases on the list. 